\title{
Os nomes gerais na escrita mineira: uma análise de cartas para o Papai Noel
}

\author{
Los nombres generales en la escritura minera: un análisis de \\ cartas para Papá Noel
}

\section{General nouns in the writing of Minas Gerais: an analysis of letters to Santa Claus}

\author{
Jeander Cristian da Silva ${ }^{1}$, Eduardo Tadeu Roque Amaral ${ }^{2}$
}

\begin{abstract}
RESUMO: Este trabalho analisa o comportamento dos nomes gerais em um corpus constituído por cartas destinadas ao Papai Noel, realizando um contraste entre os dados da modalidade escrita e resultados anteriores obtidos com dados de língua oral. A análise se baseia em estudos semânticos e sociolinguísticos sobre os nomes gerais e leva em conta também as propriedades do gênero textual carta. São observados aspectos quantitativos, especialmente aqueles relativos à frequência desses nomes, e qualitativos, relacionados à concordância nominal, à foricidade e à relação dos nomes com certos pronomes indefinidos. Como resultado principal, verifica-se que, analisando-se as marcas de oralidade, o escrevente mantém certa preocupação com suas escolhas lexicais, afastando-se um pouco do texto oral no que se refere ao emprego dos nomes gerais. Ao se considerar a faixa etária dos informantes, observa-se que crianças e jovens demonstram uma leve preferência pelo uso de uma pessoa em oposição ao emprego do pronome indefinido alguém.
\end{abstract}

Palavras-chave: Nomes gerais. Cartas. Língua Portuguesa.

RESUMEN: En este trabajo se analiza el comportamiento de los nombres generales en un corpus constituido por cartas destinadas a Papá Noel, realizando un contraste entre los datos de la modalidad escrita y resultados anteriores obtenidos con datos de lengua oral. El análisis se basa en estudios semánticos y sociolingüísticos sobre los nombres generales y

\footnotetext{
${ }^{1}$ Mestrando do Programa de Pós-Graduação em Estudos Linguísticos da Universidade Federal de Minas Gerais. E-mail: jeandercristian@gmail.com.

2 Professor associado da Faculdade de Letras da Universidade Federal de Minas Gerais. E-mail: eduamaralbh@ufmg.br.
} 
Os nomes gerais na escrita mineira: uma análise de cartas para o Papai Noel

tiene en cuenta también las propiedades del género textual carta. Se observan aspectos cuantitativos, especialmente aquellos relacionados a la frecuencia de esos nombres, y cualitativos, relacionados a la concordancia nominal, la "foricidad" y la relación de los nombres con algunos pronombres indefinidos. Como resultado principal, se observa que, al analizar las marcas de oralidad, el remitente mantiene cierta preocupación por la selección léxica, alejándose un poco del texto oral en lo que se refiere al empleo de los nombres generales. Cuando se considera la franja etaria de los informantes, se observa que niños y jóvenes demuestran una leve preferencia por el uso de uma pessoa (una persona) en oposición al empleo del pronombre indefinido alguém (alguien).

Palabras-clave: Nombres generales. Cartas. Lengua Portuguesa.

ABSTRACT: This paper analyses the behavior of the general nouns in a corpus composed by letters sent to Santa Claus and contrasts these written language data with previous results from spoken language data. The analysis is based on semantic and sociolinguistic studies about the general nouns and also takes into account the properties of the letters as a textual genre. It is observed quantitative aspects, especially related to the frequency and the relation of those nouns with some indefinite pronouns. By analysing the oral features, as a main result, it is verified that the sender worries about his/her lexical choices and moves away a little from the oral text regarding the use of the general nouns. Considering the age range of the informers, it is observed that children and young people have a slight preference for using uma pessoa (a person) in opposition to the indefinite pronoun alguém (someone).

Keywords: General nouns. Letters. Portuguese language.

\section{Introdução}

Neste estudo, objetiva-se analisar o comportamento de nomes gerais na escrita mineira a partir de um corpus constituído por cartas escritas para o Papai Noel e enviadas aos Correios. De acordo com a instituição, a partir do momento em que começaram a chegar cartas endereçadas ao Papai Noel, a tradicional campanha Papai Noel dos correios foi criada, de modo a evitar que os remetentes ficassem sem resposta (CORREIOS, 2015). Desse modo, quem desejasse prestar um ato de solidariedade poderia realizar o pedido desses escreventes, que compreende desde brinquedos, até roupas, materiais escolares e cestas básicas. A autoria é composta, em sua maioria, por crianças carentes (ou seus representantes), que utilizam o 
Os nomes gerais na escrita mineira: uma análise de cartas para o Papai Noel

espaço para desabafar sobre suas realidades e fazer o pedido do tão sonhado presente do Papai Noel. No ano de 2012, cerca de mil cartas foram doadas à UFMG para integrar o corpus do projeto de pesquisa Cartas ao Papai Noel: a escrita em Minas Gerais ${ }^{3}$.

Constituem nomes gerais certas unidades linguísticas cuja definição é composta apenas por traços semânticos muito genéricos, tais como [+/- humano] ou [+/- contável] (MIHATSCH, 2006) e, desse modo, são itens dotados de uma intensão mínima e uma extensão máxima (KOCH; OESTERREICHER, 2007). São exemplos: coisa, negócio, pessoa, indivíduo, etc. Além disso, são usados, em geral, quando o falante não sabe, não quer ou não pode dizer o nome do referente (KLEIBER, 1987).

Alguns trabalhos recentes têm investigado o comportamento dessa categoria de nomes no português brasileiro. Amaral e Ramos (2014), por exemplo, analisam o estatuto desses itens em dados de língua oral coletados em Minas Gerais, descrevendo suas propriedades gramaticais, textuais e sociolinguísticas, e evidenciando os traços que esses itens apresentam em comum com os pronomes. No que diz respeito a este estudo, objetiva-se analisar esses nomes no corpus de cartas citado. Como essas cartas apresentam muitos traços linguísticos da oralidade, a hipótese deste trabalho é que, na escrita informal, esses itens podem compartilhar propriedades encontradas na fala.

Na próxima seção, apresenta-se o marco teórico em que se insere este trabalho, o qual compreende os estudos sobre os nomes gerais e sobre o gênero carta. Em seguida, explicam-se os procedimentos metodológicos adotados para a constituição do corpus de cartas endereçadas ao Papai Noel, bem como aqueles relativos à análise das ocorrências dos nomes gerais. Posteriormente, são analisados os dados encontrados, antes de serem expostas as conclusões.

\footnotetext{
${ }^{3} \mathrm{O}$ projeto, no qual este trabalho está inserido, é executado na Faculdade de Letras da UFMG, sob coordenação geral do prof. Dr. Lorenzo Vitral.
} 
Os nomes gerais na escrita mineira: uma análise de cartas para o Papai Noel

\section{Fundamentação Teórica}

Em geral, Halliday e Hasan (1995) são considerados os precursores dos estudos sobre os nomes gerais, ou, como denominado por eles, general nouns ${ }^{4}$. De acordo com esses autores, o nome geral é um "caso limítrofe entre um item lexical (membro de um conjunto aberto) e um item gramatical (membro de um sistema fechado)" (HALLIDAY; HASAN 1995, p. 274). No entanto, do ponto de vista semântico-lexical, esses itens assumem uma função coesiva, já que seriam membros superordenados de grandes conjuntos lexicais; do ponto de vista gramatical, a combinação desses itens com um determinante específico seria bem semelhante a um item referencial.

Mahlberg (2005), numa abordagem centrada na linguística de corpus, estudou a frequência e o comportamento textual de vinte elementos encontrados no Bank of English Corpus. time, year, people, years, world, way, day, life, man, part, end, women, place, things, men, business, family, thing, times, woman. A autora considera que só se pode descrever o significado desses nomes analisando 0 contexto em que aparecem e se houver ocorrências repetidas desses mesmos itens.

Estudos recentes da linguística textual exploram a função coesiva dos nomes gerais. Koch (2004, p. 250), por exemplo, afirma: "outra forma de retomada anafórica é a que se faz por meio de nomes genéricos, tais como coisa, pessoa, negócio, criatura, indivíduo". No mesmo sentido, Marcuschi e Koch (2006) destacam que, na língua falada, é muito comum o uso desses nomes, por serem mais acessíveis do que um termo mais específico. Anteriormente, Fulgêncio (1983) já havia esclarecido que o falante, ao fazer uso desses termos, acredita que o sentido possa ser inferido pelo ouvinte, através do universo textual.

\footnotetext{
${ }^{4}$ Autores mais antigos, como Havers (1931), já chamavam a atenção para elementos desse tipo na linguagem coloquial. Para uma abordagem de caráter contrastivo, veja-se também Koch e Oesterreicher (2007).
} 
Os nomes gerais na escrita mineira: uma análise de cartas para o Papai Noel

Por sua vez, Amaral e Ramos (2014) analisam o estatuto categorial dos nomes gerais descrevendo suas propriedades gramaticais, textuais e sociolinguísticas, e apontando os traços em comum que esses itens mantêm com os pronomes. Morfologicamente, alguns desses nomes não apresentam marcas nem de gênero nem de número; mesmo que o determinante se realize no plural, tais itens se realizam no singular (os trem; os negócio). A análise do item coisa mostra que esse item pode ser considerado como nome geral por excelência, em vista de sua grande ocorrência; além disso, parece funcionar como uma raiz à qual se somam afixos verbais ou nominais como: coisei, coiso, coisável. Do ponto de vista semântico, a perda de conteúdo referencial transmite aos nomes gerais uma função fórica. 0 conjunto de propriedades analisadas têm levado os autores à confirmação de que os nomes gerais se assemelham, em certos traços, aos pronomes.

Com efeito, o conjunto de unidades linguísticas que designam conceitos gerais em um nível elevado de generalização constitui uma fonte importante para a formação de pronomes em muitas línguas, conforme já demonstrado por outros autores (HASPELMATH, 1997; HEINE; KUTEVA, 2004; HEINE; SONG, 2011; LEHMANN, 1995; MIHATSCH, 2017). Estudos recentes que incluem dados do português brasileiro têm demonstrado que a forma pessoa já apresenta traços de pronominalização (AMARAL; MIHATSCH, 2019).

Apesar de haver uma série de pesquisas que vêm sendo desenvolvidas sobre os nomes gerais nos últimos anos, tal como apontado anteriormente, nenhuma delas observa o comportamento desses itens no gênero carta. Por esse motivo, neste trabalho, busca-se verificar se os traços que os nomes gerais apresentam em dados de língua oral se assemelham aos da escrita nesse gênero, tais como a ausência de marcação de plural, a foricidade e sua aproximação com as construções pronominais. A hipótese é que as cartas, por apresentarem certas marcas de oralidade, também mantêm características dos nomes gerais identificadas na língua oral. 
Os nomes gerais na escrita mineira: uma análise de cartas para o Papai Noel

A carta é um gênero textual que viabiliza a construção de relações interativas à distância. Considerando que a prática de seu uso deve atender às necessidades comunicativas de cada situação apresentada, Bex (1996, p. 157) esquematiza a divisão desse gênero em cartas públicas - de estilo formal (ex: carta comercial, carta de cobrança, carta à redação, memorando, ofício, dentre outras) e cartas privadas - de estilo informal (ex: carta de amor e carta pessoal). A carta ao Papai Noel é um tipo que se aproxima muito da carta pessoal, pela informalidade e pela relação de afetividade entre os remetentes. Quem escreve faz um pedido de um presente para um ser fictício, porém muito íntimo, por ser aceito culturalmente como $O$ bom velhinho, capaz de "realizar todos os pedidos e sonhos". A diferença está na dinâmica interlocutiva, que só se dá em um sentido - do remetente para destinatário - sem a possibilidade de inversão desses papéis. O Papai Noel, de fato, nunca assumirá o papel de remetente para responder sobre o pedido daquele que enviou a carta.

Com relação ao estilo, observa-se que o diálogo nas cartas apresenta marcas comuns da oralidade. Os exemplos abaixo, encontrados no corpus, evidenciam tais aspectos: o tratamento informal (1); a ausência de concordância nominal (2) e verbal (3); construções com gerúndio típicas da oralidade (4).

(1) Se você não puder me dar nem uma das 4 coisas, pode ser algu que você possa comprar!!! (C. 36)

(2) Meu nome é [...] eu tenho dois irmao um chamado [...] com 14 anos, e outro chamado [...] com 10 anos, e eu com 7 anos. (C. 31)

(3) conto com a tua ajuda porque eles não cuida só de mim tenho mais dois irmãos Pequeno. (C. 721)

(4) se não é pedir muito gostaria de estar pedindo 4 coisas. (C.36)

\footnotetext{
5 Manteve-se, nos exemplos, a grafia original, conforme se explica na próxima seção. Entre parênteses, incluem-se os números das cartas no corpus.
} 
Os nomes gerais na escrita mineira: uma análise de cartas para o Papai Noel

No exemplo (1), verifica-se o uso do pronome de segunda pessoa você em lugar de um tratamento mais respeitoso como, por exemplo, o senhor. Em (2), a ausência de concordância de número do substantivo irmão com o quantificador dois. Em (3), a ausência de concordância de número e pessoa do verbo cuidar com o sujeito eles. Em (4), o famoso gerundismo, fenômeno típico da fala contemporânea, recebedor de um forte estigma. A partir dessas amostras, é possível reafirmar a hipótese de que, na escrita das cartas ao Papai Noel, poderiam ser encontrados traços que os nomes gerais apresentam na oralidade.

\section{Procedimentos Metodológicos}

Neste trabalho, analisa-se o conteúdo de 694 cartas, que totalizam 65.818 tokens e 6.680 types. A preparação do corpus se deu em diferentes etapas: a primeira foi a ocultação de dados pessoais, tais como: nomes, endereços e telefones, por questões de ética. Em seguida, procedeu-se à transcrição para o formato .txt, a qual buscou-se ser o mais fidedigna possível, respeitando, assim, a estrutura e o conteúdo das cartas.

Como exemplo, observa-se, em (5), que o texto transcrito registra a grafia Noeu tal como se lê no original, e a forma abreviada BJS para beijos. Da mesma forma, mantém-se, em (6), a presença do verbo pedir não flexionado na $1^{\text {a }}$ pessoa do singular do pretérito perfeito do indicativo e o uso das formas escreve-se e ahinda, no lugar de escrevesse e ainda, respectivamente. Também se observa a ausência da marca de infinitivo em escreve.

(5) Fragmento da carta 8

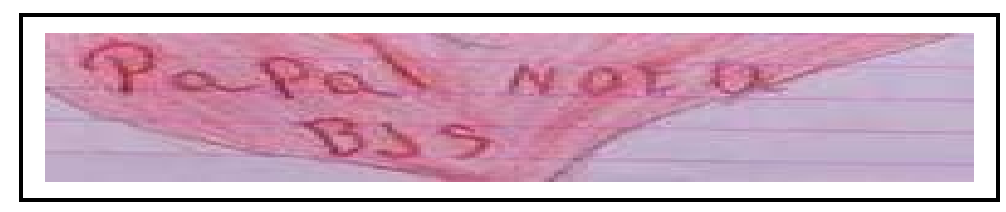


Os nomes gerais na escrita mineira: uma análise de cartas para o Papai Noel

Papai Noeu

BJS

(6) Fragmento da carta 460

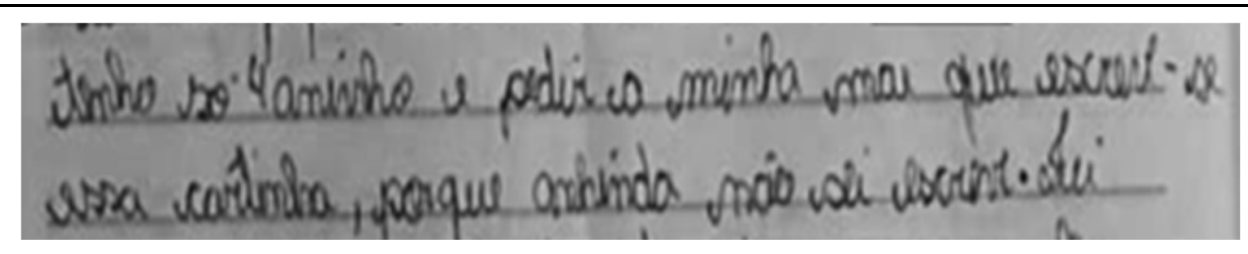

"tenho só 4 aninho e pedir a minha mae que escreve-se essa cartinha, porque anhinda não sei escreve. Fui(...)"

Como ferramenta para a análise, foi utilizado o software AntConc 3.2.4 (ANTHONY, 2018) na execução dos seguintes procedimentos: listagem do número total de palavras apresentadas no corpus; listagem das palavras-chave, tomando outro corpus, com dados de língua oral mineira, como referência6; e listagem da frequência dos itens pesquisados. $\mathrm{Na}$ análise dos dados apresentada a seguir, são observados aspectos relativos à frequência e às propriedades gramaticais e semântico-textuais dos dados.

\section{Análise dos Dados}

Em uma análise inicial dos dados, verifica-se que os nomes gerais não estão entre as primeiras palavras-chave do corpus. Tendo como parâmetro de referência dados de língua oral mineira e utilizando a ferramenta Keyword List do programa Antconc, observa-se que, no conjunto de substantivos e verbos, esses elementos estão mais relacionados ao campo semântico de 'Natal', tal como mostra o Quadro 1.

\footnotetext{
${ }^{6}$ Os dados de língua oral são constituídos por gravações sociolinguísticas e fazem parte do projeto $O$ uso dos nomes gerais nos falares mineiros. Uma amostra pode ser consultada no site: www.letras.ufmg.br/nomesgerais.
} 
Os nomes gerais na escrita mineira: uma análise de cartas para o Papai Noel

Quadro 1 - Palavras-chave do corpus (substantivos e verbos)

\begin{tabular}{|c|c|}
\hline substantivos & verbos \\
\hline 1. papai noel & 1. ganhar \\
2. natal & 2. ter \\
3. anos & 3. gostar \\
4. presente & 4. estar \\
5. senhor & 5. pedir \\
6. sonho & 6. dar \\
7. nome & 7. chamar \\
8. mãe & 8. comprar \\
9. carta & 9. poder \\
10. material & 10. querer \\
\hline
\end{tabular}

Fonte: Autores.

O resultado exibido no Quadro 1 já era esperado, tanto pela temática das cartas, quanto pela presença de unidades lexicais e construções como Papai Noel, Natal, ganhar presente, etc. No entanto, apesar de não constituírem as palavraschave do corpus, a presença dos nomes gerais não é pequena. Em consonância com os estudos que situam esses nomes entre pronomes e substantivos lexicais (conforme já apontavam Halliday e Hasan (1995) para o nível semântico-textual), o gráfico 1 , a seguir, obtido por meio da quantificação do número de ocorrências (Word List) de palavras, mostra que essa posição intermediária também se verifica quantitativamente. Tomando-se dois pronomes da língua (ele e ela), dois nomes gerais (coisa e pessoa) e dois itens de conteúdo lexical selecionados aleatoriamente, mas frequentes no corpus (celular e computador), comprova-se, a exemplo do que Amaral e Ramos (2014) verificam para a língua oral, que, no corpus das cartas, em termos quantitativos, os nomes gerais também se encontram entre pronomes e 
Os nomes gerais na escrita mineira: uma análise de cartas para o Papai Noel

nomes comuns.

Gráfico 1 - Frequência de dois pronomes, dois nomes gerais e duas unidades lexicais no corpus

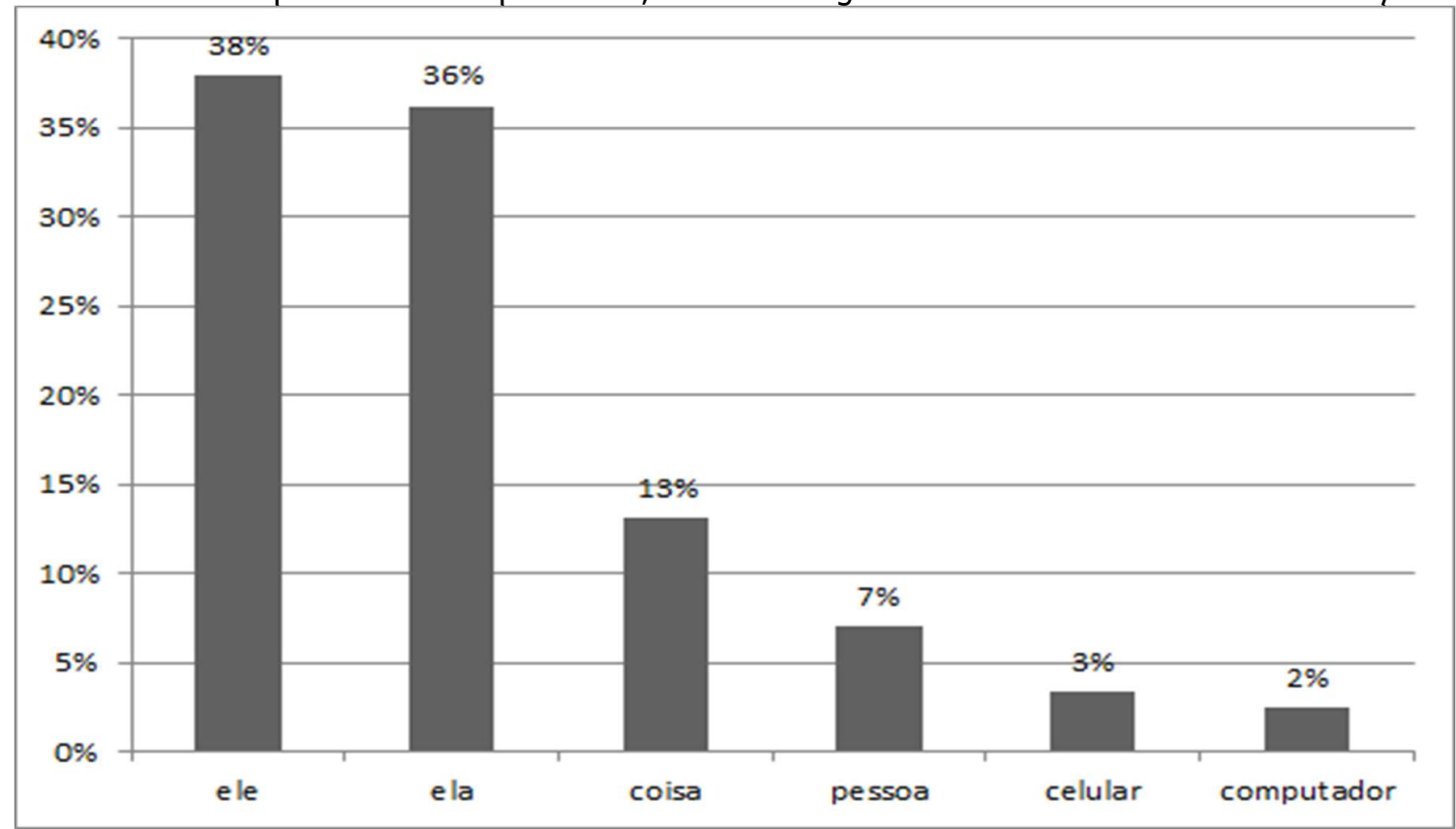

Fonte: Autores.

Com relação aos nomes gerais de traço [-humano], o corpus não apresenta ocorrência de itens como negócio e trem. Isso se deve ao fato de que esses são nomes mais comuns do discurso informal não planejado (AMARAL, 2014; AMARAL; RAMOS, 2014; RAMOS, 2013). Há apenas uma ocorrência do item troço (7), mesmo assim em um contexto de expressão fixa (dar um troço), tal como descrito por Oliveira (2017):

(7) eu to muito chateada, sem chão e to a ponto de dar um troço, nunca tive sorte com homens so queria ter paz e ser feliz [...] (C.470)

No que se refere aos nomes gerais de traço [+humano], não há, no corpus, ocorrências dos itens indivíduo, ser humano e sujeito. Isso se explica pelo fato de serem nomes geralmente utilizados em situações mais formais ou em outros gêneros textuais (AMARAL, 2017; SCHNEDECKER, 2015).

Os resultados acima comprovam a prototipicidade dos nomes coisa e pessoa 
entre os nomes gerais para referenciar, respectivamente, entidades inanimadas (sejam elas concretas ou abstratas) e entidades humanas. Em termos absolutos, são 101 ocorrências de coisa e 54 de pessoa. Por esse motivo, esses nomes serão objeto de descrição mais detalhada a seguir.

Com respeito ao comportamento gramatical dos nomes gerais, analisa-se aqui a marcação de plural. Vários estudos têm mostrado que a ausência de marcas de plural é comum no português brasileiro e Scherre (1988) já sinalizou o fato de que itens mais informais tendem a perder marcas de plural. Embora as cartas ao Papai Noel sejam um gênero escrito, verificam-se algumas ocorrências de SNs sem a marca de plural no nome, tal como mostram (8) e (9).

(8) a minha mãe deixa de comprar as coisa para nós para pagar aluguel. (C.394)

(9) que Deus te abençõe cada dia mais por ser essa pessoa tão boa para essas pessoa e eu te desejo um feliz natal (C.3)

Em termos quantitativos, porém, o fenômeno não é muito frequente. Dos 99 casos de sintagmas nominais no plural que contêm coisa e pessoa, $7 \%$ não apresentam o morfema [-s] de plural, sobretudo no item coisa, tal como se pode ver na Tabela 1.

Tabela 1 - Ausência ou presença de marcas de plural [-s]

\begin{tabular}{|c|c|c|c|}
\hline Plural & coisa & pessoa & TOTAL \\
\hline Com marca & 58 & 34 & $\mathbf{9 2}$ \\
\hline Sem marca & 6 & 1 & $\mathbf{7}$ \\
\hline Total & $\mathbf{6 4}$ & $\mathbf{3 5}$ & $\mathbf{9 9}$ \\
\hline
\end{tabular}

Fonte: Autores. 
Os nomes gerais na escrita mineira: uma análise de cartas para o Papai Noel

Dessa forma, ao analisar o aspecto da concordância nominal nas ocorrências dos nomes gerais, percebe-se que eles têm um comportamento mais típico da linguagem escrita. Isso pode ser explicado considerando-se que, embora a escrita das cartas ao Papai Noel apresente outros traços comuns da oralidade, os autores mantêm certa preocupação ao fazer suas escolhas lexicais, inclusive na concordância de número.

Sobre as propriedades fóricas do nome coisa, nota-se que os casos de catáfora são bem mais frequentes, principalmente quando o autor da carta deseja introduzir no discurso o seu pedido de natal (10). Casos de anáfora, por sua vez, ocorrem quando o escrevente retoma o seu pedido de Natal (11). De qualquer modo, verifica-se a importância fórica desses elementos, tal como comentado anteriormente.

(10) tenho 9 anos queria muito te pedir uma coisa uma que eu sempre quis ter, um celular tokisquim ou um kit de material escolar do carrocel (C. 135)

(11) hoje eu estou ti pedindo um carrinho de controle remoto. todo ano eu ti pesso a mesma coisa mas você nunca me deu.

$\mathrm{Na}$ análise dos dados, observa-se que há várias ocorrências do item coisa que se aproximam a construções pronominais. Em (12) e (13), o sintagma uma coisa pode ser substituído por algo, pronome de baixa frequência na língua oral. Observem-se as paráfrases em (12a) e (13a):

(12) Sabe papai noel tem uma coisa que eles querem muito só que eu não tenho condições de realizar o sonho deles (C.462)

(12a) Sabe papai noel tem algo que eles querem muito só que eu não tenho condições de realizar o sonho deles

(13) estou escrevendo esta carta para te pedir uma coisa uma cesta de chocolate e meterial escolar (C.844) 
Os nomes gerais na escrita mineira: uma análise de cartas para o Papai Noel

(13a) estou escrevendo esta carta para te pedir algo uma cesta de chocolate e meterial escolar

De modo similar, o corpus revela ocorrências do item pessoa que também revelam a proximidade dos nomes gerais a itens pronominais. Observe-se que, em (14) e (15), uma pessoa pode ser substituído por alguém, conforme mostram (14a) e (15b).

(14) o que importa e a boa vontade e a Confiança que esta ajudando Realmente uma Pessoa que Precisa (C. 442)

(14a) o que importa e a boa vontade e a Confiança que esta ajudando Realmente alguém que Precisa

(15) peço a Deus em primeiro lugar para enviar uma pessoa para nos ajudar ele tem 44 anos.

(15) peço a Deus em primeiro lugar para enviar alguém para nos ajudar ele tem 44 anos.

Considerando que o corpus foi estratificado por faixas etárias ${ }^{7}$ e que existem alguns contextos de uso dos nomes gerais em que é possível a substituição por um pronome indefinido, tal como mostram os exemplos (12) a (15), observamos a relação dessas ocorrências com aquelas em que o usuário já opta pelo uso do pronome. Apesar de poucas ocorrências, essa relação nos permite levantar algumas hipóteses a respeito do comportamento dos nomes gerais em relação aos pronomes indefinidos no corpus estudado. Levando-se em conta que certos nomes gerais estão associados à linguagem informal e, muitas vezes, à "pobreza lexical", procuramos investigar se entre as faixas etárias de crianças e jovens haveria maior preferência

\footnotetext{
7 Embora o projeto de pesquisa apresente uma estratificação etária do corpus, sabemos que houve interferência de adultos nas cartas assinadas por crianças ou jovens. Por exemplo, em (6), tem-se um caso de uma carta de adulto, já que o próprio remetente (uma criança de 4 anos) afirma não saber escrever e ter pedido à mãe para fazê-lo. Como não é possível ter acesso aos dados sociolinguísticos completos dos autores das cartas postadas nos Correios, a estratificação foi realizada com base em informações constantes nos próprios textos.
} 
Os nomes gerais na escrita mineira: uma análise de cartas para o Papai Noel

pelo uso dos nomes gerais em comparação com os pronomes algo e alguém.

O gráfico 2 apresenta a relação entre o nome geral coisa e seu pronome indefinido correspondente. Observa-se que não há diferenças significativas entre as faixas etárias.

Gráfico 2 - Comparação entre o nome geral coisa e o pronome indefinido algo

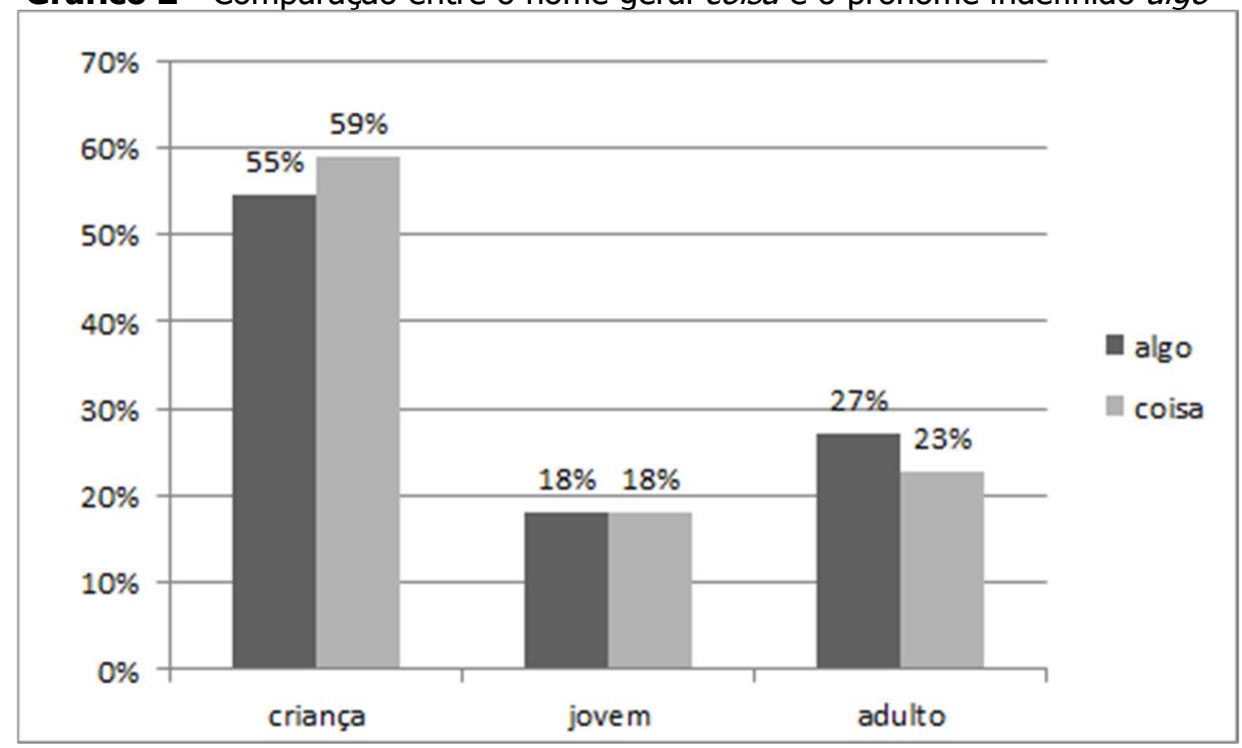

Fonte: Autores.

Em relação ao nome pessoa, é nítida a preferência, por adultos, pelo uso do pronome indefinido alguém. Nas outras faixas, por outro lado, há certa preferência pelo uso do nome geral, conforme mostra o Gráfico 3. 
Os nomes gerais na escrita mineira: uma análise de cartas para o Papai Noel

Gráfico 3 - Comparação entre o nome geral pessoa e o pronome indefinido alguém

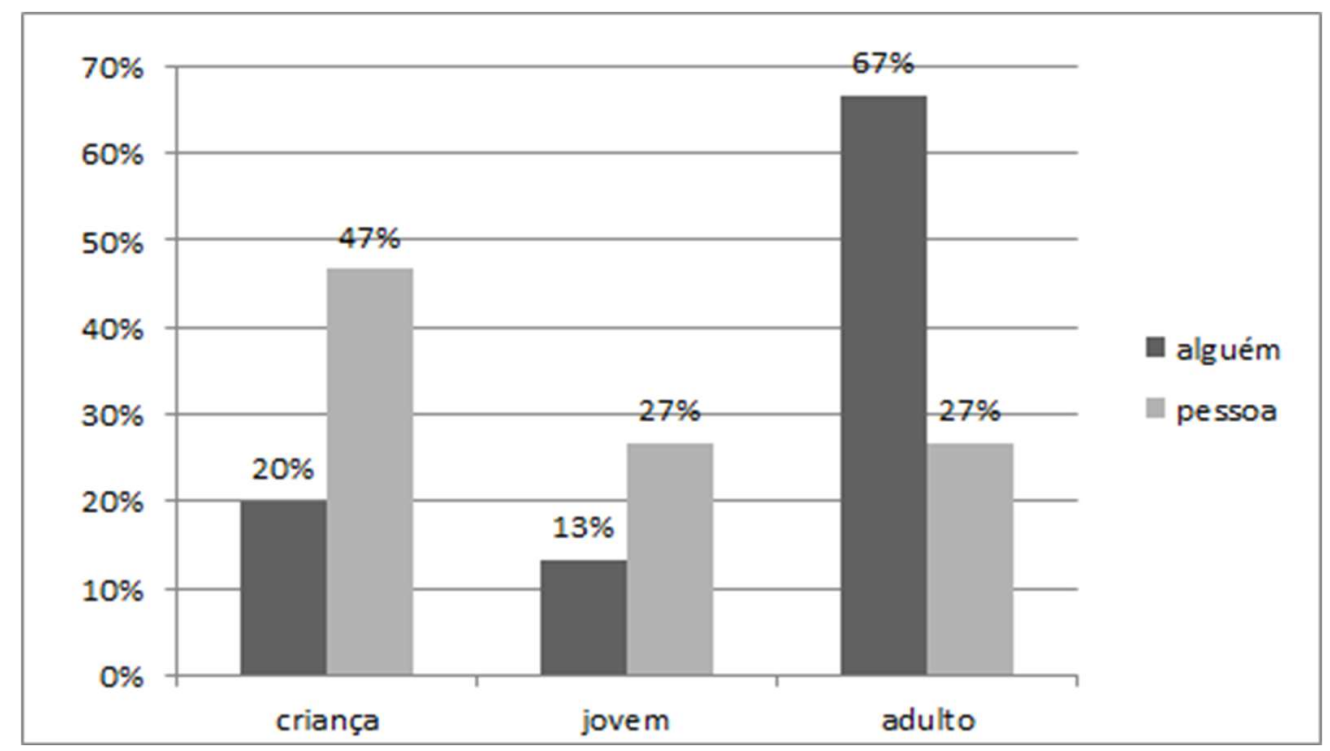

Fonte: Autores.

Esses dados acerca da relação entre os nomes e pronomes permitem verificar que há equivalências para o uso do nome geral coisa e do pronome indefinido correspondente. Por outro lado, há uma leve tendência, entre as faixas criança e jovem, para o uso do nome pessoa, se comparado ao de alguém. Esse resultado se alinha com estudos de frequência do nome geral pessoa. Se o uso dessa unidade linguística tem se ampliado no português brasileiro, é de se esperar que crianças e jovens apresentem uma maior frequência em seu emprego. Observa-se, além disso, que, no estudo do comportamento dos nomes gerais, é importante analisar não somente a variação entre nomes gerais e pronomes, mas também a influência do traço $[+/-$ humano].

\section{Considerações Finais}

O corpus escrito das cartas destinadas ao Papai Noel, embora apresente marcas morfossintáticas comuns da oralidade, afasta-se do texto oral no que se 
Os nomes gerais na escrita mineira: uma análise de cartas para o Papai Noel

refere à presença dos nomes gerais, pois não apresenta formas geralmente utilizadas pelo falante como, por exemplo, negócio e trem. Todavia, ocorrências de coisa e pessoa nos permitem corroborar a hipótese de que esses são os nomes gerais mais prototipicamente utilizados para referenciar, respectivamente, entidades com traço [-humano] e [+humano], inclusive no gênero estudado.

Esse resultado permite afirmar que, ao relacionar a presença dos nomes gerais à escolha lexical dos autores das cartas, estas se incluem em uma situação intermediária entre o discurso informal não planejado, em que é comum a frequência de uma diversidade de nomes gerais para entidades cujo nome o falante não quer, não sabe ou não pode pronunciar, e o discurso formal planejado, em que o falante utiliza muitos nomes gerais de origem culta.

Ao analisar o aspecto da concordância nominal nas ocorrências dos nomes gerais, percebe-se que eles têm um comportamento mais típico da linguagem escrita. Isso pode ser explicado considerando-se que, ainda que a escrita das cartas ao Papai Noel apresente outros traços comuns da oralidade, os autores mantêm certa preocupação ao fazer suas escolhas lexicais, inclusive na concordância de número, seja por conta dos propósitos comunicativos desse gênero em específico, seja por conta da imagem que se tem do leitor, mesmo sendo este fictício.

À exemplo do que outros pesquisadores verificaram para a língua oral, no corpus analisado, em termos quantitativos, os nomes gerais também se encontram entre pronomes e nomes comuns. Esse fato nos permitiu observar a frequência de contextos em que é possível alternar um nome geral por um pronome indefinido. Assim, ao analisar essa relação juntamente com a faixa etária, os dados levantados revelam equivalências entre o uso do nome geral coisa e do pronome indefinido algo, uma leve tendência pelo uso do nome geral pessoa, dentro da faixa etária criança e jovem, e a preferência, por adultos, pelo uso do pronome indefinido alguém. No primeiro caso, verifica-se uma situação de covariação que parece ser mais típica da modalidade escrita que da modalidade oral. No segundo caso, o 
Os nomes gerais na escrita mineira: uma análise de cartas para o Papai Noel

resultado encontrado vai ao encontro de outros trabalhos sobre o português brasileiro, em que se tem observado um incipiente processo de pronominalização no uso de pessoa, além de outros nomes (AMARAL; MIHATSCH, 2019).

\section{Referências}

AMARAL, Eduardo Tadeu Roque. Análise de um nome geral na fala dos mineiros: para que serve esse trem? Trama: Revista do Curso de Letras, Cascavel, PR, v. 10, n. 20, p. 27-44, 2014.

AMARAL, Eduardo Tadeu Roque. Estudio contrastivo de nombres generales para humanos en español y en portugués. Lingüística y Literatura, Medellín, CO, n. 72, p. 54-79, 2017.

AMARAL, Eduardo Tadeu Roque; MIHATSCH, Wiltrud. Incipient impersonal pronouns in colloquial Brazilian Portuguese based on 'pessoa', 'pessoal' and 'povo'. Linguistische Berichte, Sonderhefte, v. 26, p. 149-185, 2019.

AMARAL, Eduardo Tadeu Roque; RAMOS, Jânia M. Os nomes gerais no português brasileiro. Belo Horizonte: Faculdade de Letras da UFMG, 2014.

ANTHONY, Laurence. AntConc: a freeware corpus analysis toolkit for concordancing and text analysis. Disponível em:

http://www.antlab.sci.waseda.ac.jp/software.html. Acesso em: 20 jul. 2018.

BEX, Tony. Variety in written English: texts in society: societies in text. London: Routledge, 1996.

CORREIOS. Papai Noel dos correios. Disponível em:

http://www.correios.com.br/sobre-correios/sustentabilidade/vertente-social/papainoel-dos-correios. Acesso em: 15 out. 2015.

FULGÊNCIO, Lúcia. O problema da interpretação dos elementos anafóricos. 1983. Dissertação (Mestrado em Linguística) - Faculdade de Letras da Universidade Federal de Minas Gerais, Belo Horizonte, 1983.

HALLIDAY, Michael. A. K.; HASAN, Ruqaiya. Cohesion in English. 14. ed. London: Longman, 1995.

HASPELMATH, Martin. Indefinite pronouns. Oxford: Clarendon, 1997. (Oxford 
Os nomes gerais na escrita mineira: uma análise de cartas para o Papai Noel

studies in typology and linguistic theory).

HAVERS, Wilhelm. Handbuch der erklärenden Syntax: ein Versuch zur Erforschung der Bedingungen und Triebkräfte in Syntax und Stilistik. Heidelberg: Carl Winters Universitätsbuchhandlung, 1931.

HEINE, Bernd; KUTEVA, Tania. World lexicon of grammaticalization. Cambridge: Cambridge University Press, 2004.

HEINE, Bernd; SONG, Kyung-an. On the grammaticalization of personal pronouns. Journal of Linguistics, Cambridge, GB, v. 47, n. 3, p. 587-630, 2011.

KLEIBER, Georges. Mais à quoi sert donc le mot chose? Une situation paradoxale. Langue Française, Paris, FR, v. 73, p. 109-128, 1987.

$\mathrm{KOCH}$, Ingedore G. V. Sobre a seleção do núcleo das formas nominais anafóricas na progressão referencial. In: NEGRI, Lígia; FOLTRAN, Maria J.; OLIVEIRA, Roberta P. (org.). Sentido e significação: em torno da obra de Rodolfo Ilari. São Paulo: Contexto, 2004. p. 244-262.

KOCH, Peter; OESTERREICHER, Wulf. Lengua hablada en la Romania: español, francés, italiano. Madrid: Gredos, 2007.

LEHMANN, Christian. Thoughts on grammaticalization. München, NCA: LINCOM Europa, 1995.

MAHLBERG, Michaela. English general nouns. a corpus theoretical approach. Amsterdam: John Benjamins Publishing, 2005.

MARCUSCHI, Luiz Antonio; KOCH, Ingedore G. V. Referenciação. In: JUBRAN, Clélia C. A. S.; KOCH, Ingedore G. V. Gramática do português culto falado no Brasil: construção do texto falado. Campinas: UNICAMP, 2006. v. 1, p. 381-399.

MIHATSCH, Wiltrud. Kognitive Grundlagen lexikalischer Hierarchien: untersucht am Beispiel des Französischen und Spanischen. Tübingen: Max Niemeyer, 2006.

MIHATSCH, Wiltrud. Les noms d'humains généraux aux limites de la grammaticalisation. Syntaxe et Sémantique, Caen, FR, v. 18, p. 67-99, 2017.

OLIVEIRA, Luanna de Sousa do Nascimento. Expressões fixas do português formadas a partir de nomes gerais: aspectos lexicais e variacionistas. 2017. Dissertação (Mestrado em Estudos Linguísticos) - Faculdade de Letras da Universidade Federal de Minas Gerais, Belo Horizonte, 2017. 
Os nomes gerais na escrita mineira: uma análise de cartas para o Papai Noel

RAMOS, Jânia M. O surgimento de um nome geral: a lexia trem no dialeto mineiro. In: RAMOS, Jânia M.; COELHO, Sueli M. Português brasileiro dialetal: temas gramaticais. Campinas: Mercado de Letras, 2013. p. 137-147.

SCHERRE, Maria Marta P. Reanálise da concordância nominal em português. 1988. Tese (Doutorado em Linguística) - Faculdade de Letras da Universidade Federal do Rio de Janeiro, Rio de Janeiro, 1988.

SCHNEDECKER, Catherine. Les (noms d') humains sont-ils à part? Intérêts linguistiques d'une sous-catégorie nominale encore marginale. In: MIHATSCH, Wiltrud; SCHNEDECKER, Catherine. Les noms d'humains. une catégorie à part? Stuttgart: Franz Steiner, 2015. p. 15-53. 